\title{
Los servicios y las políticas de estímulo a la I+D: un estudio comparativo entre sectores e instrumentos
}

\author{
Isabel Busom \\ Universitat Autònoma de Barcelona \\ Beatriz Corchuelo \\ Universidad de Extremadura \\ Ester Martínez-Ros \\ Universidad Carlos III de Madrid
}

\section{Resumen}

¿Siguen las empresas de servicios el mismo patrón de participación en las políticas públicas de estímulo a la I $+D$ que las empresas manufactureras? ¿Es necesario diseñar políticas distintas atendiendo al sector productivo? En este artículo pretendemos dar algunas respuestas a partir de la evidencia empírica obtenida con una muestra de empresas de ambos sectores. Para ello comparamos el uso de incentivos fiscales y ayudas directas en ambos sectores y su asociación con determinadas características empresariales. Los principales resultados apuntan a que no existe un sesgo en beneficio del sector manufacturero, y que las principales diferencias entre empresas residen principalmente en sus capacidades para el desarrollo de actividades de $I+D$.

Palabras clave: $I+D$, subvenciones, incentivos fiscales, servicios, manufacturas.

Clasificación JEL: H25, L60, O38.

\begin{abstract}
Do service and manufacturing firms differ in their access to public policies supporting $R \& D$ ? Does each industry need a different innovation policy? In this paper we provide some empirical evidence that may contribute to answer these questions. We compare the use of tax incentives and direct support in both industries, and their correlation with some firm features. Our results hint that these policies do not particularly favor manufacturing firms, and that the main differences across firms' access arise mostly from differences in human capital and firm capabilities.
\end{abstract}

Keywords: $R \& D$, tax incentives, services, manufacturing firms.

JEL classification: H25, L60, O38.

\section{Introducción}

En la Estrategia Europea 2020, acordada por los estados miembros en junio de 2010, y en particular en la recientemente lanzada llamada «Innovation Union», se perfila una estrategia de innovación global para Europa donde se reconoce a la 
innovación como herramienta fundamental de crecimiento. Sus objetivos fundamentales son la mejora del acceso a la financiación de la innovación y del éxito de sus resultados, de forma que las ideas innovadoras puedan transformarse en productos y servicios que creen empleos y contribuyan al crecimiento. El impulso de la inversión privada en actividades innovadoras es un elemento clave de esta estrategia.

Las políticas de innovación desarrolladas en muchos países tienen como uno de sus objetivos básicos una mayor implicación por parte de las empresas. Pero para conseguir impulsar la inversión privada, es importante entender qué incentivos tienen las empresas para llevarla a cabo, es decir, cuáles son los retornos empresariales de las inversiones. Las inversiones en innovación pueden ser de distinto tipo pero su objetivo es siempre incrementar el stock de conocimiento de la empresa para encontrar nuevas aplicaciones o mejoras de las ya existentes que contribuyan a un mayor beneficio. Así, la inversión en innovación acometida por una empresa puede mejorar la productividad de la misma mejorando la calidad de los bienes o servicios que produce, reduciendo los costes de los mismos o simplemente ampliando el espectro de bienes o servicios que ofrece. Por lo tanto, la innovación es una fuente de ventajas comparativas y de mercado para las empresas.

El estudio de los estímulos a las actividades privadas de desarrollo e innovación propiciados desde la administración se ha principalmente centrado en el sector manufacturas. Esto ha sido así porque este sector ha tenido históricamente un peso importante en el PIB, y la medición de innovaciones en el mismo es relativamente mensurable al poderse identificar nuevos productos o nuevos procesos de producción asociados a los esfuerzos en inversión por parte de las empresas. Según el Informe PITEC 2010, observamos que en el año 2008, inicio del período de crisis, el peso de la inversión en actividades innovadoras sobre la cifra de negocios estaba en torno al 1,35 por 100 en la industria mientras que para el sector servicios dicho peso era de tan solo el 0,75 por 100. Por tamaños, la brecha era mayor en la industria (con 0,98 para PYMES y un 1,64 para empresas grandes) que en los servicios (un 0,60 y un 0,91 , respectivamente). Si comparamos la evolución del gasto en innovación, observamos que este presentó un comportamiento más negativo en las empresas de servicios, situándose su tasa de crecimiento entre 2007 y 2008 en el $-1,7$ por 100 , mientras que en las manufacturas, con un recorte del $-0,8$ por 100 , mantuvo la tendencia que se ha venido produciendo en años anteriores. Dicho comportamiento negativo se ha intensificado en el caso de las empresas de servicios hasta alcanzar una tasa de crecimiento en el período 2009-2010 del -9,3 por 100, mientras que se produce una recuperación en las manufacturas con un incremento del 7,9 por 100 en comparación a los años anteriores.

A pesar de los progresos realizados durante los años previos a la crisis, España sigue mostrando importantes debilidades, en comparación con otros países miembros de la OCDE, tanto por los menores recursos privados destinados a la I+D como por el bajo nivel de los resultados derivados de dicho esfuerzo. Como se observa en el Gráfico 1, siendo el quinto país por número de empresas, en el año 2008 tan solo teníamos un 43,5 por 100 de empresas innovadoras, 8 puntos porcentuales por 
debajo de la media de la Unión Europea y por debajo de países como Portugal, Irlanda o República Checa.

Parte de las diferencias que se observan en el Gráfico 1 pueden ser atribuibles a la diversa composición sectorial de cada economía, es decir, al peso relativo de industria y servicios, así como a su vez a la composición dentro de cada uno de estos sectores. Pero otros factores también influyen, y pueden tener una importancia mayor.

\section{GRÁFICO 1}

LA EMPRESA INNOVADORA EN EUROPA (2008). \% DE EMPRESAS INNOVADORAS SOBRE EL TOTAL DE EMPRESAS

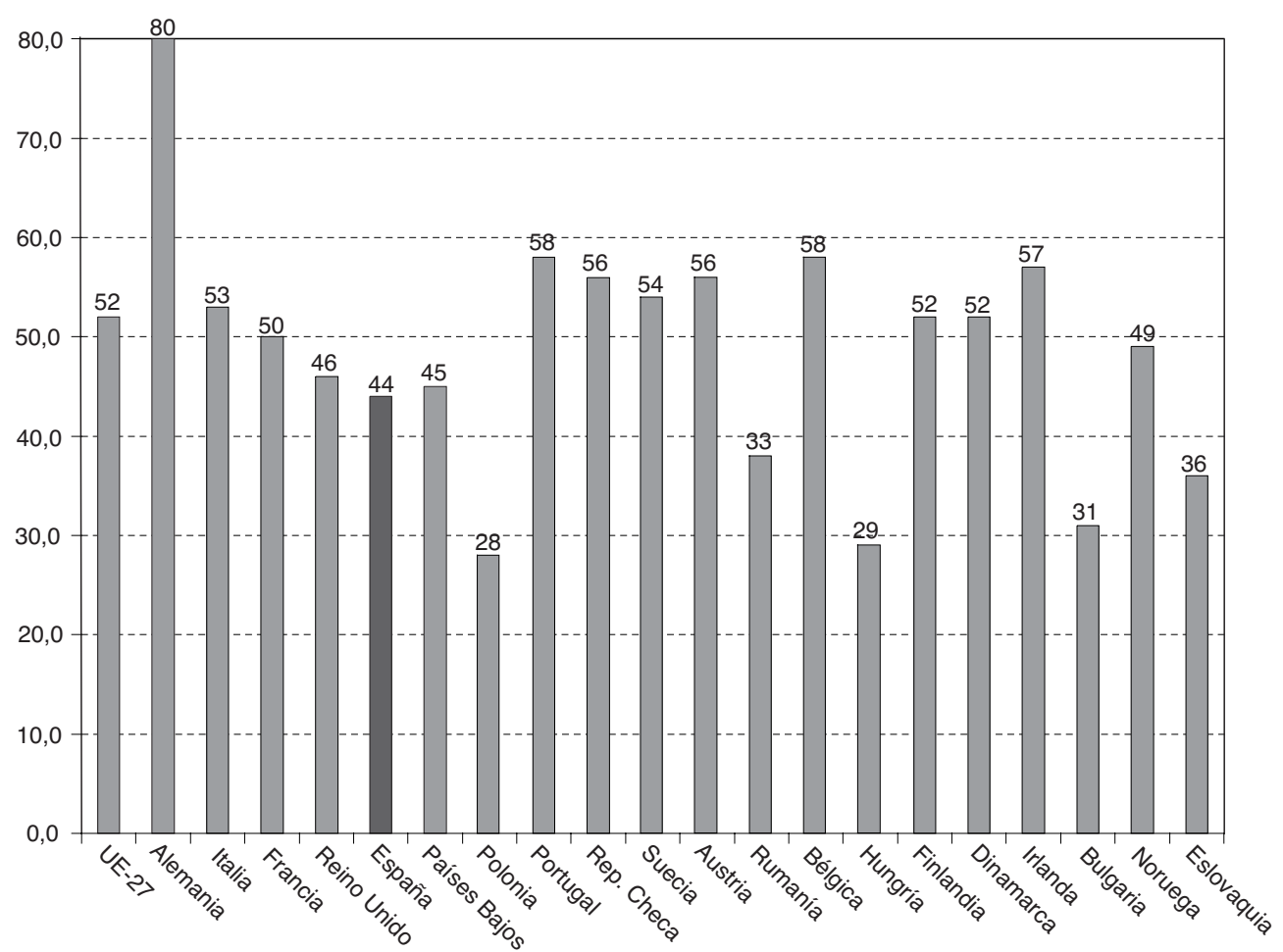

FUENTE Eurostat, CIS6. 2008.

Si comparamos algunos indicadores para estos dos grandes sectores entre España y uno de los países más avanzados en este sentido en la Unión Europea, Suecia, observamos en el Cuadro 1 que en ambos España muestra un nivel innovador más bajo, lo que sugiere que el origen de las dificultades para innovar puede no estar tanto en la especialización sectorial sino en factores de carácter más general, como pueden ser la disponibilidad y nivel del capital humano, las posibles barreras al nacimiento, crecimiento y transformación de empresas, el acceso a instrumentos financieros, o ciertas características del marco legal. 
CUADRO 1

INNOVACIÓN EN LAS MANUFACTURAS Y SERVICIOS (ESPAÑA Y SUECIA, 2012)

\begin{tabular}{|l|c|c|c|c|}
\hline \multirow{2}{*}{} & \multicolumn{2}{|c|}{ Manufacturas } & \multicolumn{2}{c|}{ Servicios } \\
\cline { 2 - 5 } & España & Suecia & España & Suecia \\
\hline $\begin{array}{l}\text { Número total de empresas/población } \\
(\%)\end{array}$ & 28,5 & 49,3 & 18,6 & 43,2 \\
\hline $\begin{array}{l}\text { Empresas que desarrollan innovacio- } \\
\text { nes de producto y/o proceso mediante } \\
\text { la adaptación o modificación de pro- } \\
\text { ductos, servicios o procesos original- } \\
\text { mente desarrollados por otras empre- } \\
\text { sas o instituciones/empresas que rea- } \\
\text { lizan I+D (\%) }\end{array}$ & 4,6 & 16,4 & 3,3 & 18,7 \\
\hline $\begin{array}{l}\text { Empresas que desarrollan innovacio- } \\
\text { nes de producto y/o proceso conjun- } \\
\text { tamente con otras empresas o insti- } \\
\text { tuciones/empresas que realizan I+D } \\
(\%)\end{array}$ & 13,9 & 37,4 & 11,8 & 29,3 \\
\hline $\begin{array}{l}\text { Empresas que desarrollan innova- } \\
\text { ciones de producto y/o proceso por sí } \\
\text { mismas/empresas que realizan I+D } \\
(\%)\end{array}$ & 36,2 & 55,2 & 27,9 & 47,5 \\
\hline
\end{tabular}

FUENTE: Eurostat, CIS 2012.

Ambos países cuentan con políticas públicas de apoyo a la I+D. En España se ofrecen ayudas directas e incentivos fiscales a la inversión en I+D desde hace muchos años; en estudios comparativos entre países de la OCDE, los incentivos fiscales en España han estado entre los más elevados de los países miembros. En Suecia se han utilizado durante mucho tiempo solo ayudas directas, y no incentivos fiscales; éstos se han introducido muy recientemente. Por tanto, los indicadores mostrados en el Cuadro 1 muestran la necesidad de investigar hasta qué punto las medidas de estímulo a la I+D e innovación en vigor son efectivas.

El trabajo que aquí se presenta trata de contrastar si el patrón de comportamiento de las empresas manufactureras es similar al de las empresas de servicios en cuanto a la participación en el uso de dos instrumentos disponibles en España y en otros países de la OCDE: las ayudas directas y los incentivos fiscales a la inversión en I+D. Para ello, se utilizan los datos de la muestra de empresas que ofrece el Panel de Innovación Tecnológica (PITEC), elaborado por el INE, correspondientes a dos oleadas de datos: 2003-2005 y 2006-2008. 
Los principales resultados del análisis apuntan a que no hay evidencia de sesgo positivo en políticas públicas de estímulo a la I+D en favor del sector de las manufacturas y en perjuicio de las empresas del sector de servicios. Tras estudiar las características de las empresas concluimos que el capital humano de las mismas, así como el tamaño en ciertos casos, son los principales condicionantes en la participación de las empresas en los distintos instrumentos públicos de incentivo a la $\mathrm{I}+\mathrm{D}$ en vigor durante el período analizado. En la medida en que en el sector servicios se encuentran subsectores más intensivos en capital humano, que es la fuente de las ideas para la innovación, y que el nivel del mismo aumente, se observará un mayor acceso de los mismos a los mecanismos públicos de apoyo.

Este artículo se organiza como sigue: en la sección 2 se analiza el estado de la cuestión; la sección 3 presentan los datos y una descripción de los mismos; la sección 4 muestra y discute los resultados de las estimaciones; finalmente, en la sección 5 se concluye.

\section{Las ayudas públicas a la I+D: justificación y evaluación}

\subsection{La justificación económica}

El análisis de la capacidad del mercado, como mecanismo de asignación de recursos, de conducir a una asignación eficiente predice que, en el caso de las actividades de $\mathrm{I}+\mathrm{D}$, se puede producir una menor inversión de la que sería socialmente deseable. Dos características de las mismas conducen a esta conclusión. Primero, la inversión en I+D está dirigida a generar conocimiento nuevo -información-que como tal tiene rasgos de bien público: puede ser no rival y no excluible. Es decir, la posibilidad de establecer y respetar derechos de propiedad es limitada, y por tanto los incentivos privados (empresariales en este caso) para producirla se verán mermados. Otro factor que conduce a la sub-provisión privada de inversión en I+D se deriva de la existencia de diferencias de información e incentivos entre los inversores potenciales y los inventores, que repercuten negativamente en la disponibilidad de financiación para estas actividades.

La evidencia empírica disponible da apoyo a estas predicciones, por lo que está justificado buscar formas adecuadas de intervención pública para modificar los incentivos privados de forma que se produzca el nivel de inversión en I+D deseado, que es aquel en el que el coste marginal social de la inversión iguala el beneficio marginal social. Las ayudas directas -subvenciones o créditos blandos-,y las indirectas -incentivos fiscales- son dos instrumentos que potencialmente pueden modificar los incentivos privados, en la medida en que ambos reducen el coste que supone a la empresa llevar a cabo actividades de $\mathrm{I}+\mathrm{D}^{1}$. Es de esperar que cualquier empresa que

\footnotetext{
${ }^{1}$ No son éstos los únicos instrumentos de una política de estímulo a la innovación: los sistemas legales de protección de la propiedad industrial e intelectual y el apoyo a nuevas empresas basadas en el conocimiento mediante capital semilla son algunos de ellos.
} 
ya estuviera haciendo I+D considere utilizar alguno de estos instrumentos o ambos, modificando o no la cantidad o características de sus proyectos de I+D. También es posible que algunas empresas que hasta el momento no realizaban actividades de innovación o que no colaboraban para innovar se planteen hacerlo.

De las empresas potencialmente interesadas en solicitar ayudas directas o en aplicar los incentivos fiscales, la agencia o agencias públicas deberían seleccionar idealmente aquellos proyectos que reunieran ciertas características, asociadas a la situación de fallos de mercado, que es lo que justifica la implantación de los instrumentos. Esta selección se puede realizar examinando las características de los proyectos que se presentan a convocatorias de ayudas directas o, en el caso de los incentivos fiscales, mediante un diseño que permita acotar las deducciones a través de la definición de los tipos de gastos deducibles, la diferenciación según el tamaño de la empresa y el carácter de la deducción (sobre el volumen total de gastos deducibles o sobre los incrementos de dicho gasto). En ambos casos, el objetivo debe ser estimular innovaciones socialmente rentables que no se hubiesen realizado de otro modo.

Resulta oportuno destacar aquí que, en el contexto de la Unión Europea, las ayudas estatales están prohibidas (artículo 87, apartado 1 del Tratado), siendo las destinadas a fomentar la I+D una de las excepciones a esta regla. La condición que deben cumplir estas ayudas es que se refieran a «actividades concretas e inequívocamente encaminadas a remediar deficiencias del mercado que impidan la innovación y tales que sea probable que los beneficios de las ayudas estatales que se les otorguen compensen con creces cualquier posible perjuicio que puedan causar a la competencia y el comercio» (Comisión Europea, Diario Oficial de la Unión Europea, C 323/01, apartado $1.2[11,12])$.

Por otro lado, el diseño de los incentivos fiscales también debería discriminar entre aquellos que los usan como una forma de pagar menos impuestos, de los que realmente están dispuestos a invertir más en I+D como consecuencia de la reducción implícita de su coste.

\subsection{La evaluación de la política de innovación}

El diseño y aplicación de los instrumentos mencionados no es fácil, debido a las dificultades intrínsecas que comporta la información necesaria y la valoración de riesgos y externalidades positivas generadas por los proyectos que solicitan y reciben el apoyo público. Por ello es fundamental evaluar ex-post sus resultados e impactos diversos. Nuestro trabajo se enmarca dentro de la literatura que analiza desde distintas perspectivas la existencia, uso y eficacia de diversos instrumentos financieros de las Administraciones para estimular la inversión privada en $\mathrm{I}+\mathrm{D}$. 
Encontramos muchos estudios tanto a nivel internacional como español, casi siempre referidos al sector secundario, que analizan uno a uno los distintos instrumentos. Varios estudios panorámicos dan cuenta de los métodos, datos y resultados obtenidos en lo que podemos llamar una primera generación de estudios de evaluación: Hall y Van Reenen (2000), David, Hall y Toole (2000) y Klette, Mohen y Griliches (2000); el primero en relación con los incentivos fiscales y los dos últimos en relación con las ayudas directas. Más recientemente, Cerulli (2010) ofrece una revisión actualizada de las investigaciones empíricas que se han seguido produciendo ${ }^{2}$. Sin embargo, prácticamente sigue sin disponerse de estudios comparativos de uso y efectividad de los instrumentos en los distintos sectores.

Aunque la disponibilidad de datos adecuados es una fuente importante de dificultades para la investigación, es posible estudiar algunos aspectos a los que no se ha dedicado mucha atención. Por ejemplo, el análisis económico predice, como hemos dicho antes, que las restricciones para financiar la innovación y la dificultad de apropiabilidad de los resultados potenciales son obstáculos importantes para la inversión empresarial en I+D. Sin embargo, las especificaciones que se suelen estimar en las investigaciones empíricas no guardan un vínculo estrecho con dichas hipótesis. Una excepción la encontramos en el trabajo de Gelabert, Fosfuri y Tribó (2009), quienes estudian el impacto que tienen en España las ayudas directas sobre la inversión privada en I+D teniendo en cuenta el grado de apropiabilidad y de restricciones financieras de las empresas. El resultado principal de sus estimaciones es que la elasticidad de la inversión privada en I+D con respecto a la subvención recibida varía según la dificultad de apropiabilidad y la dificultad de financiación ${ }^{3}$. Sin embargo, este trabajo no tiene en cuenta que las empresas podían acogerse al mismo tiempo a incentivos fiscales, lo que puede distorsionar los resultados obtenidos.

Otra cuestión sobre la que no existe suficiente evidencia empírica es la relativa a la respuesta de las empresas a las políticas de apoyo a la I+D en función del tipo de sector productivo, es decir, si hay diferencias destacables entre el sector industrial y el de servicios. Este último incluye una gran variedad de subsectores: servicios financieros, inmobiliarios, personales, comercio minorista y mayorista, servicios a empresas, servicios de comunicación e información, etcétera. Sin duda, una de las dimensiones en las que esta diversidad se manifiesta es en la innovación: mientras en unos esta se basa principalmente en adoptar innovaciones de proceso generadas en otros sectores (los proveedores), otros generan innovaciones genuinas. Casos como

\footnotetext{
${ }^{2}$ El Cuadro A1 del Anexo sintetiza los resultados más destacados de las investigaciones previas.

3 Según nuestros cálculos, realizados a partir de los resultados obtenidos por los autores, la elasticidad sería de 0,53 para un nivel nulo de apropiabilidad y máximo de dificultad de financiación. Para la situación opuesta, de máxima apropiabilidad y nulas restricciones financieras, la elasticidad estimada tendría un valor de $-0,38$; este último valor correspondería a un efecto de sustitución parcial de inversión privada por pública. La elasticidad aumentaría con la dificultad de apropiabilidad, si bien es superior cuando la empresa tiene dificultades de financiación que cuando tiene dificultades de apropiabilidad. Estos valores serían coherentes con la argumentación económica.
} 
Google con su diversificación en materia de introducción de innovaciones (coche autónomo, gafas de lectura y traducción) o la industria hotelera con innovaciones en materia de mejoras en el medio ambiente o desarrollo o adopción de tecnologías para ampliar la cartera de clientes, ilustran la variedad y heterogeneidad dentro de la categoría global de servicios ${ }^{4}$.

Solo conocemos un estudio que explícitamente aborde el impacto de las ayudas directas a la I+D empresarial en el sector servicios. Se trata del trabajo de Czarnitzki y Fier (2002), quienes estudian el caso de las empresas alemanas. Con una muestra de corte transversal, y aplicando métodos no paramétricos, rechazan la hipótesis de un efecto completo de expulsión de inversión privada por pública, al igual que se ha obtenido en estudios para la industria. Sin embargo, no se analiza la participación en sí misma en los programas públicos, ni se compara con instrumentos alternativos como los incentivos fiscales, simplemente porque éstos no se ofrecen en Alemania.

Recientemente Busom, Corchuelo y Martínez Ros (2014) han analizado conjuntamente la participación de las empresas españolas en las dos formas de apoyo, contrastando su grado de correlación con indicadores de restricciones financieras y de apropiabilidad. Como se argumenta en dicho artículo, las ayudas directas y los incentivos fiscales presentan características distintas en términos de requisitos para acceder a los mismos, cuantía y certeza de la ayuda en relación a los costes del proyecto, y momento de percepción de la ayuda. Ello hace prever que el incentivo efectivo que cada uno representa varíe en función de la razón por la que una empresa pueda estar invirtiendo menos de lo deseable en I+D. En concreto, es improbable que los incentivos fiscales, que ofrecen deducciones de la cuota del impuesto sobre sociedades en función de la cuantía de la inversión en I+D, puedan ser atractivos para empresas que se enfrentan a dificultades para financiar nuevos proyectos; para ello el mecanismo de ayudas directas sería más apropiado. Lo mismo puede ocurrir si la causa de la insuficiente inversión se halla en las dificultades de apropiabilidad debido a la amenaza de imitación de los resultados del proyecto (externalidades positivas del conocimiento).

Los resultados de las estimaciones realizadas para una muestra de empresas industriales españolas, apuntan a que dicha correlación varía en función del instrumento y del tamaño de la empresa. La probabilidad de utilizar incentivos fiscales se reduce cuando la empresa se enfrenta a dificultades de financiación de la I+D, pero en cambio aumenta la probabilidad de obtener ayudas directas. Globalmente, se confirma la hipótesis de que los incentivos fiscales y las ayudas directas no son substitutos a la hora de decidir su uso por parte de las empresas. Nuestro objetivo aquí es estudiar el acceso de las empresas del sector servicios a los instrumentos de apoyo a la I+D, y compararlo con las del sector industrial. Ello ha de permitir contrastar si las posibilidades de apropiación de los retornos de la innovación y la

\footnotetext{
${ }^{4}$ Por ello es habitual distinguir entre los servicios según su intensidad tecnológica, de forma semejante a como se hace en la industria.
} 
capacidad de encontrar financiación para llevar a cabo los proyectos juegan el mismo papel en la obtención de apoyo público que en el caso de las empresas industriales.

\section{Los datos}

El INE viene realizando la Encuesta sobre Innovación en las Empresas (EIT) desde el año 1994. La EIT incluye, entre otras, preguntas sobre introducción de innovaciones, gastos en innovación, fuentes de ideas innovadoras, así como sobre la percepción empresarial relativas a determinados obstáculos a la innovación. Para propiciar la investigación sobre este tema, el INE y la FECYT ofrecen datos anonimizados de una muestra de la EIT, el Panel de Innovación Tecnológica (PITEC), disponible para los años 2003 a 20125 . El PITEC contiene alrededor de 12000 empresas cuyo grado de representatividad de la población depende del tamaño de la empresa. Mientras que la muestra es representativa de la población para las empresas de 200 o más trabajadores, en el caso de las que tienen menos de 200, y a pesar de que contiene empresas sin gastos en innovación, la muestra está sesgada hacia las que tienen gastos de I+D (interna o externa).

El Cuadro 2 muestra el porcentaje y número de empresas industriales y de servicios con actividades de innovación que han recibido ayudas directas de las distintas administraciones públicas desde el año 2005 hasta 2011. Observamos que el porcentaje de empresas con financiación pública es mayor en la industria que en los servicios, si bien es cierto que en los últimos años ha aumentado más en el sector de los servicios. También se han acercado en cifras absolutas el número de empresas de los dos sectores que reciben ayudas directas de las administraciones autonómicas y de la administración central. La diferencia es sustancial en el caso de las ayudas de la Unión Europea.

Para este artículo utilizamos dos oleadas del PITEC: la de 2003-2005 y la de 2006-2008. Nuestra muestra incluye 4437 empresas del sector de manufacturas, y 3.626 empresas del sector de servicios ${ }^{6}$. Dado que nuestro objetivo es comparar el uso de los incentivos fiscales, que son de ámbito estatal, con las ayudas directas, consideramos que dentro de estas es adecuado seleccionar las de ámbito estatal. Por otra parte, una característica del cuestionario que responden las empresas incluye algunas preguntas que se refieren a un período de tres años. Por esta razón para nuestro estudio utilizamos el período 2006-8 para definir las variables objeto de interés, que son las de acceso a las ayudas directas y a los incentivos fiscales. El Gráfico 2 muestra, por tamaño de empresa y por sector, el estado de las empresas de la muestra en relación con el acceso a los dos tipos de apoyo público a la inversión empresarial en I+D en España.

\footnotetext{
5 Véase FECYT (2010) y COTEC (2010).

${ }^{6}$ Nuestras muestras incluyen solo las empresas para las que tenemos información de todas las variables usadas en las estimaciones que presentamos en el apartado siguiente. Además, excluimos de la muestra aquellas empresas que manifiestan no tener interés por innovar debido a la falta de demanda o a que ya lo han hecho en períodos anteriores.
} 


\section{CUADRO 2}

LA FINANCIACIÓN PÚBLICA DE LA INNOVACIÓN POR SECTORES PRODUCTIVOS (2008-2010)

\begin{tabular}{|c|c|c|c|c|c|c|c|c|}
\hline \multirow{3}{*}{ Años } & \multirow{2}{*}{\multicolumn{2}{|c|}{$\begin{array}{c}\text { \% empresas EIN } \\
\text { con financiación } \\
\text { pública }\end{array}$}} & \multicolumn{6}{|c|}{ Empresas EIN que han recibido financiación pública } \\
\hline & & & \multicolumn{2}{|c|}{$\begin{array}{c}\text { De } \\
\text { Administraciones } \\
\text { Locales o } \\
\text { Autonómicas }\end{array}$} & \multicolumn{2}{|c|}{$\begin{array}{c}\text { De la } \\
\text { Administración } \\
\text { Central }\end{array}$} & \multicolumn{2}{|c|}{$\begin{array}{c}\text { De la Unión } \\
\text { Europea }\end{array}$} \\
\hline & Industria & Servicios & Industria & Servicios & Industria & Servicios & Industria & Servicios \\
\hline 2005 & 28,38 & 17,86 & 3.853 & 2.957 & 2.148 & 1.860 & 554 & 54 \\
\hline 2006 & 25,71 & 14,3 & 3.146 & 2.262 & 1.956 & 1.534 & 330 & 46 \\
\hline 2007 & 25,27 & 16,65 & 3.100 & 2.463 & 2.076 & 1.980 & 288 & 35 \\
\hline 2008 & 28,51 & 21,56 & 3.176 & 3.041 & 2.024 & 2.511 & 276 & 45 \\
\hline 2009 & 28,72 & 21,55 & 3.116 & 3.093 & 2.102 & 2.378 & 326 & 52 \\
\hline 2010 & 28,8 & 20,28 & 2.408 & 2.400 & 1.997 & 1.945 & 299 & 48 \\
\hline 2011 & 28,95 & 21,26 & 1.932 & 1.953 & 1.840 & 1.973 & 338 & 45 \\
\hline
\end{tabular}

FUENTE: INE, Encuesta sobre Innovación Tecnológica.

NOTA: EIN indica Empresas Innovadoras o con innovaciones en curso o no exitosas.

\section{GRÁFICO 2}

EL ACCESO AL APOYO PÚBLICO VINCULADO A INVERSIÓN EN I+D (En \%)
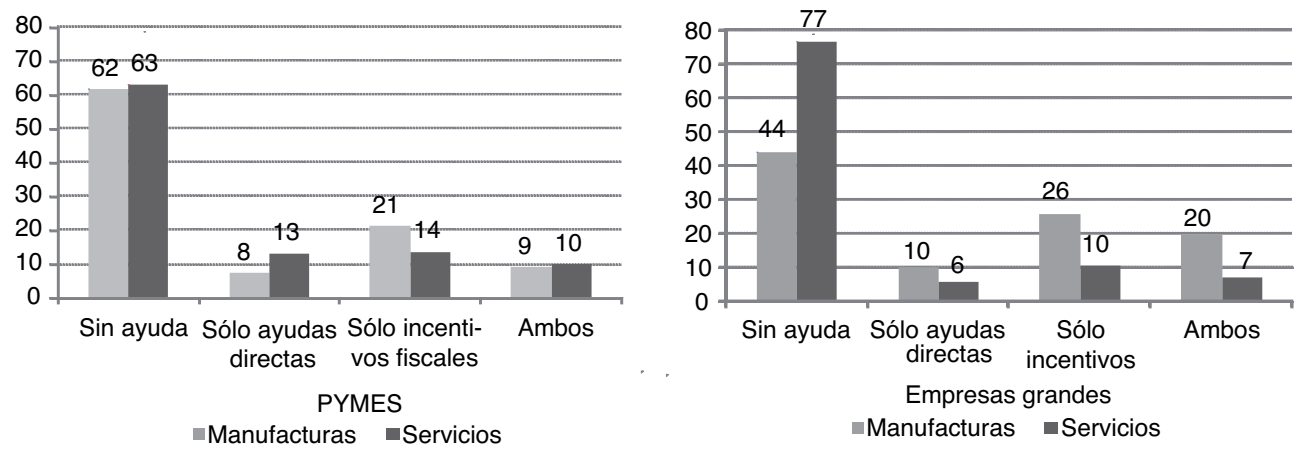

FUENTE: Elaboración propia en base a los datos del PITEC, años 2006 a 2008. 
Los datos del gráfico muestran que hay pocas diferencias entre PYMES manufactureras y de servicios en cuanto al acceso al apoyo público. La principal diferencia que se observa es que las empresas de servicios tienen proporcionalmente mayor acceso a subvenciones que a incentivos fiscales. Entre las empresas grandes hay diferencias notables según el sector al que pertenezcan: el porcentaje de empresas que no acceden a ayudas es muy superior en el sector servicios, y especialmente el uso de incentivos fiscales en dicho sector es mucho más bajo. Cierta explicación seguramente la podríamos encontrar en la propia composición del sector de servicios, en el que tienen un peso importante aquellos subsectores donde la innovación se produce mediante la adopción de procesos o productos generados por empresas industriales.

Este argumento se vería reforzado por las cifras de las empresas situadas en sectores altamente tecnológicos. El Gráfico 3 compara el acceso al apoyo público de las Pymes en sectores de servicios donde la intensidad de conocimiento es elevada con el acceso de las Pymes en el sector de manufacturas. Se pone de relieve que el porcentaje de empresas que no cuentan con ayuda es menor que en las manufacturas, y la participación de las empresas de este subsector de servicios en las ayudas directas es más elevada, mientras que el uso de incentivos fiscales es menor.

\section{GRÁFICO 3}

\section{USO DE APOYO PÚBLICO A LA I+D EN EMPRESAS DE SERVICIOS}

INTENSIVOS EN CONOCIMIENTO

(En \%)

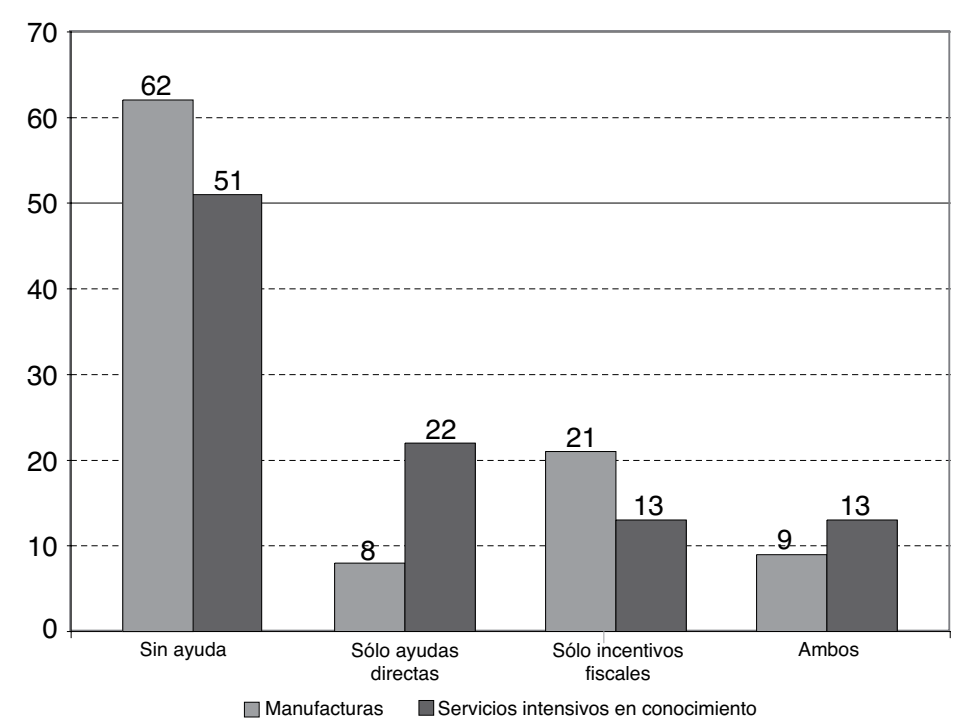

FUENTE: Elaboración propia en base a los datos del PITEC, años 2006 a 2008. 
A continuación describimos los tipos de actividad innovadora y el tipo de innovación que se realiza en cada sector según el tamaño de las empresas en el año 2008. Las actividades de innovación incluyen la inversión en I+D en la propia empresa, pero también la contratación de I+D a terceros, inversión en equipo específico, adquisición de conocimientos externos, inversión en distribución de los nuevos productos o servicios, en formación y en comercialización. Por lo que respecta a los tipos de innovación, se distingue entre innovación en productos o servicios, innovación en procesos productivos, innovación organizativa e innovación comercial. El Cuadro 3a presenta los datos de la muestra del PITEC por tamaño de empresa y por sector. En el caso de las Pymes, el porcentaje de empresas de servicios de la muestra en el año 2008 que se dedica a cada una de las actividades de innovación es muy similar al de las empresas manufactureras. Solo destaca que el porcentaje de empresas con gastos en adquisición de conocimientos externos es mayor entre las empresas de servicios, especialmente para aquellas que reciben los dos tipos de apoyo público. Tampoco hay diferencias notables en cuanto al tipo de innovación que realizan las empresas de los dos sectores. En ambos casos la actividad innovadora es mayor entre las empresas que reciben apoyo ${ }^{7}$.

La imagen es distinta en el caso de las empresas grandes (Cuadro 3b). Entre las empresas que no reciben apoyo público, el porcentaje de las que invierten en I+D, sea interna o externa, es mucho menor en servicios que en el caso de las empresas manufactureras. Este menor porcentaje de dedicación a la I+D no está compensado por una mayor inversión en equipo, aunque sí en parte por una mayor inversión en adquisición de conocimientos externos. En cuanto al tipo de innovación que hacen las empresas en el sector de servicios, aquellas que reciben apoyo se comportan de forma muy similar a las manufactureras, introduciendo innovaciones de productos, procesos y restantes. En cambio, las que no lo reciben registran una tasa mucho menor de innovaciones de proceso o producto, aunque no organizativa.

\footnotetext{
${ }^{7}$ Se debe tener en cuenta que la muestra del PITEC está por construcción sesgada, en el caso de las Pymes, hacia empresas con actividades de innovación. No es por tanto representativa de la población.
} 


\section{CUADRO 3A}

TIPOS DE ACTIVIDADES DE INNOVACIÓN Y TIPO DE INNOVACIÓN EN 2008 POR SECTOR Y APOYO PÚBLICO (PYMES)

(\% de empresas)

\begin{tabular}{|l|c|c|c|c|c|c|c|c|}
\hline \multicolumn{1}{|c|}{ PYMES } & \multicolumn{4}{|c|}{ Manufacturas } & \multicolumn{4}{c|}{ Servicios } \\
\cline { 2 - 9 } & $\begin{array}{c}\text { Sin } \\
\text { ayuda }\end{array}$ & $\begin{array}{c}\text { Solo } \\
\text { subven- } \\
\text { ciones }\end{array}$ & Solo IF & Ambas & $\begin{array}{c}\text { Sin } \\
\text { ayuda }\end{array}$ & $\begin{array}{c}\text { Solo } \\
\text { subven- } \\
\text { ciones }\end{array}$ & Solo IF & Ambas \\
\hline $\begin{array}{l}\text { Tiene gastos internos } \\
\text { en I+D }\end{array}$ & 0,48 & 0,53 & 0,79 & 0,90 & 0,38 & 0,58 & 0,73 & 0,92 \\
\hline $\begin{array}{l}\text { Tiene gastos externos } \\
\text { en I+D }\end{array}$ & 0,15 & 0,21 & 0,35 & 0,50 & 0,13 & 0,25 & 0,35 & 0,46 \\
\hline $\begin{array}{l}\text { Tiene gastos en } \\
\text { maquinaria }\end{array}$ & 0,14 & 0,18 & 0,17 & 0,21 & 0,13 & 0,17 & 0,16 & 0,21 \\
\hline $\begin{array}{l}\text { Tiene gastos en } \\
\text { adquisición } \\
\text { conocimientos externos }\end{array}$ & 0,01 & 0,01 & 0,02 & 0,02 & 0,01 & 0,02 & 0,01 & 0,05 \\
\hline $\begin{array}{l}\text { Tiene gastos en } \\
\text { distribución }\end{array}$ & 0,06 & 0,06 & 0,11 & 0,12 & 0,03 & 0,08 & 0,08 & 0,10 \\
\hline $\begin{array}{l}\text { Tiene gastos en } \\
\text { formación }\end{array}$ & 0,06 & 0,08 & 0,12 & 0,18 & 0,07 & 0,12 & 0,09 & 0,20 \\
\hline $\begin{array}{l}\text { Tiene gastos en } \\
\text { marketing }\end{array}$ & 0,14 & 0,19 & 0,24 & 0,31 & 0,11 & 0,19 & 0,20 & 0,28 \\
\hline $\begin{array}{l}\text { Innovación en } \\
\text { productos }\end{array}$ & 0,55 & 0,59 & 0,81 & 0,82 & 0,44 & 0,54 & 0,74 & 0,77 \\
\hline Innovación en procesos & 0,55 & 0,58 & 0,70 & 0,75 & 0,45 & 0,52 & 0,56 & 0,64 \\
\hline Innovación organizativa & 0,41 & 0,41 & 0,56 & 0,61 & 0,38 & 0,49 & 0,60 & 0,64 \\
\hline Innovación comercial & 0,29 & 0,28 & 0,40 & 0,43 & 0,20 & 0,27 & 0,42 & 0,40 \\
\hline Número de empresas & 1.630 & 793 & 650 & 446 & 1.085 & 631 & 255 & 300 \\
\hline
\end{tabular}


CUADRO 3B

TIPOS DE ACTIVIDADES DE INNOVACIÓN Y TIPO DE INNOVACIÓN EN 2008 POR SECTOR Y APOYO PÚBLICO (GRANDES)

(\% de empresas)

\begin{tabular}{|l|c|c|c|c|c|c|c|c|}
\hline \multicolumn{1}{|c|}{ Grandes } & \multicolumn{4}{|c|}{ Manufacturas } & \multicolumn{4}{c|}{ Servicios } \\
\cline { 2 - 10 } & $\begin{array}{c}\text { Sin } \\
\text { ayuda }\end{array}$ & $\begin{array}{c}\text { Solo } \\
\text { subven- } \\
\text { ciones }\end{array}$ & Solo IF & Ambas & $\begin{array}{c}\text { Sin } \\
\text { ayuda }\end{array}$ & $\begin{array}{c}\text { Solo } \\
\text { subven- } \\
\text { ciones }\end{array}$ & Solo IF & Ambas \\
\hline $\begin{array}{l}\text { Tiene gastos internos } \\
\text { en I+D }\end{array}$ & 0,45 & 0,64 & 0,90 & 0,94 & 0,13 & 0,30 & 0,77 & 0,85 \\
\hline $\begin{array}{l}\text { Tiene gastos externos } \\
\text { en I+D }\end{array}$ & 0,23 & 0,41 & 0,53 & 0,65 & 0,09 & 0,15 & 0,55 & 0,51 \\
\hline $\begin{array}{l}\text { Tiene gastos en } \\
\text { maquinaria }\end{array}$ & 0,20 & 0,25 & 0,26 & 0,27 & 0,17 & 0,20 & 0,28 & 0,32 \\
\hline $\begin{array}{l}\text { Tiene gastos en } \\
\text { adquisición de } \\
\text { conocimientos externos }\end{array}$ & 0,02 & 0,03 & 0,05 & 0,08 & 0,02 & 0,04 & 0,10 & 0,11 \\
\hline $\begin{array}{l}\text { Tiene gastos en } \\
\text { distribución }\end{array}$ & 0,08 & 0,08 & 0,13 & 0,17 & 0,04 & 0,01 & 0,17 & 0,22 \\
\hline $\begin{array}{l}\text { Tiene gastos en } \\
\text { formación }\end{array}$ & 0,08 & 0,19 & 0,18 & 0,24 & 0,08 & 0,11 & 0,18 & 0,19 \\
\hline $\begin{array}{l}\text { Tiene gastos en } \\
\text { marketing }\end{array}$ & 0,17 & 0,21 & 0,29 & 0,35 & 0,08 & 0,10 & 0,31 & 0,38 \\
\hline $\begin{array}{l}\text { Innovación en } \\
\text { productos }\end{array}$ & 0,56 & 0,69 & 0,87 & 0,86 & 0,23 & 0,32 & 0,76 & 0,74 \\
\hline Innovación en procesos & 0,63 & 0,74 & 0,84 & 0,88 & 0,41 & 0,42 & 0,80 & 0,86 \\
\hline Innovación organizativa & 0,47 & 0,58 & 0,73 & 0,74 & 0,41 & 0,43 & 0,67 & 0,83 \\
\hline Innovación comercial & 0,27 & 0,30 & 0,40 & 0,45 & 0,18 & 0,16 & 0,44 & 0,42 \\
\hline Número de empresas & 293 & 137 & 200 & 157 & 614 & 232 & 91 & 76 \\
\hline
\end{tabular}




\section{Estimaciones y resultados}

Para nuestro estudio hemos planteado la estimación conjunta de dos ecuaciones en las que las respectivas variables dependientes son el acceso a ayudas directas y el acceso a deducciones fiscales. Ambas son variables cualitativas binarias: una empresa accede o no a la ayuda directa, y obtiene o no una deducción fiscal. Por tanto, especificamos y estimamos un modelo probit bivariante a partir del cual se obtienen resultados de cuatro categorías excluyentes: empresas que obtienen los dos tipos de ayuda, empresas que solo acceden a las ayudas directas, empresas que solo aplican deducciones fiscales y empresas que no reciben ningún tipo de ayuda pública. Las principales variables independientes de interés son dos indicadores que son una aproximación a los factores que originan los fallos de mercado a los que hemos aludido en apartados anteriores: si la empresa se enfrenta a falta de fondos para financiar los proyectos de innovación, y si la empresa ha utilizado sistemas legales de protección de la propiedad intelectual, como aproximación al grado de apropiabilidad del esfuerzo en I+D. Ambos indicadores están referidos al período 2003-2005, de forma que se pueden considerar como variables predeterminadas.

También tenemos en cuenta un conjunto de otras variables que pueden estar correlacionadas con el acceso a ambas formas de apoyo público. Todas estas variables están referidas asimismo al período 2003-2005. Se trata de otros obstáculos a la innovación percibidos por la empresa, como el grado de riesgo percibido, la existencia de una empresa dominante en el sector o la falta de personal y de información sobre tecnología; del capital humano de la misma, medido por el porcentaje de empleados con educación superior; de la productividad de la empresa en relación con la de su subsector; del tamaño de la empresa; de la inversión en bienes de equipo como aproximación a las expectativas de la demanda; de su pertenencia a un grupo y si realiza actividad exportadora; si se trata de una nueva empresa; una variable que indica el ratio de novedad del producto en el mercado en relación a la empresa; variables que informan de si la I+D realizada por la empresa es continua u ocasional, y de localización de las empresas y acceso a otros tipos de apoyo público (ayudas de la comunidad autónoma o de la Unión Europea) ${ }^{8}$. Realizamos la estimación por separado para PYMES y para empresas grandes y diferenciando, asimismo, entre empresas de servicios y manufacturas.

\section{Pymes}

El Cuadro 4 muestra el efecto marginal medio (EMM) correspondiente a cada variable independiente en el caso de las PYMES de ambos sectores. Es decir, cada coeficiente indica en promedio cuánto cambia la probabilidad de estar en uno de

\footnotetext{
${ }^{8}$ En el Cuadro A2 del Anexo se presenta información relativa a la construcción de las principales variables empleadas para la estimación.
} 
los cuatro estados posibles en cuanto al uso de apoyo público si se produce una variación en cada variable independiente por separado. Las estimaciones nos permiten apreciar las coincidencias y discrepancias entre ambos sectores; ambas se manifiestan más nítidamente al comparar la obtención de solo ayudas directas con la obtención de solo deducciones fiscales. Entre las coincidencias observamos la asociación fundamental entre el capital humano de la empresa y la probabilidad de obtener apoyo público, especialmente ayudas directas o estas en combinación con deducciones fiscales. No disponer de capital humano reduce en gran medida esta probabilidad, mientras que tener un porcentaje importante de titulados superiores la aumenta. Esto no es sorprendente, puesto que la capacidad de innovación surge de las personas y equipos. Tampoco sorprende que sean las empresas con experiencia previa en I+D las que tiendan a aprovechar este apoyo. También hay coincidencia en que haber recibido ayudas directas de las CCAA o de la UE aumenta la probabilidad de obtenerlas de la Administración Central. Curiosamente, estas últimas están negativamente correlacionadas con la probabilidad de obtener deducciones fiscales, lo que sugiere que la naturaleza de los correspondientes proyectos de I+D será bastante distinta. También observamos un comportamiento similar en relación con la probabilidad de usar incentivos fiscales o ayudas directas por parte de empresas nuevas basadas en el conocimiento: esta circunstancia reduce el uso de deducciones fiscales, pero en cambio aumenta el de ayudas directas en ambos sectores.

Examinamos ahora las diferencias entre los dos sectores. La más relevante para las hipótesis que investigamos es que la asociación entre restricciones financieras y protección de la propiedad intelectual y uso de cada ayuda es nula en el caso de los servicios, mientras sí que existe en el caso de las empresas en el sector de manufacturas. El tamaño de la empresa tampoco juega un papel significativo en el caso de servicios. Finalmente, el grado de actividad genuinamente novedosa en el mercado no aparece relacionado con el uso de ninguno de los dos tipos de ayuda, a diferencia de lo que ocurre en el caso de las empresas manufactureras. 


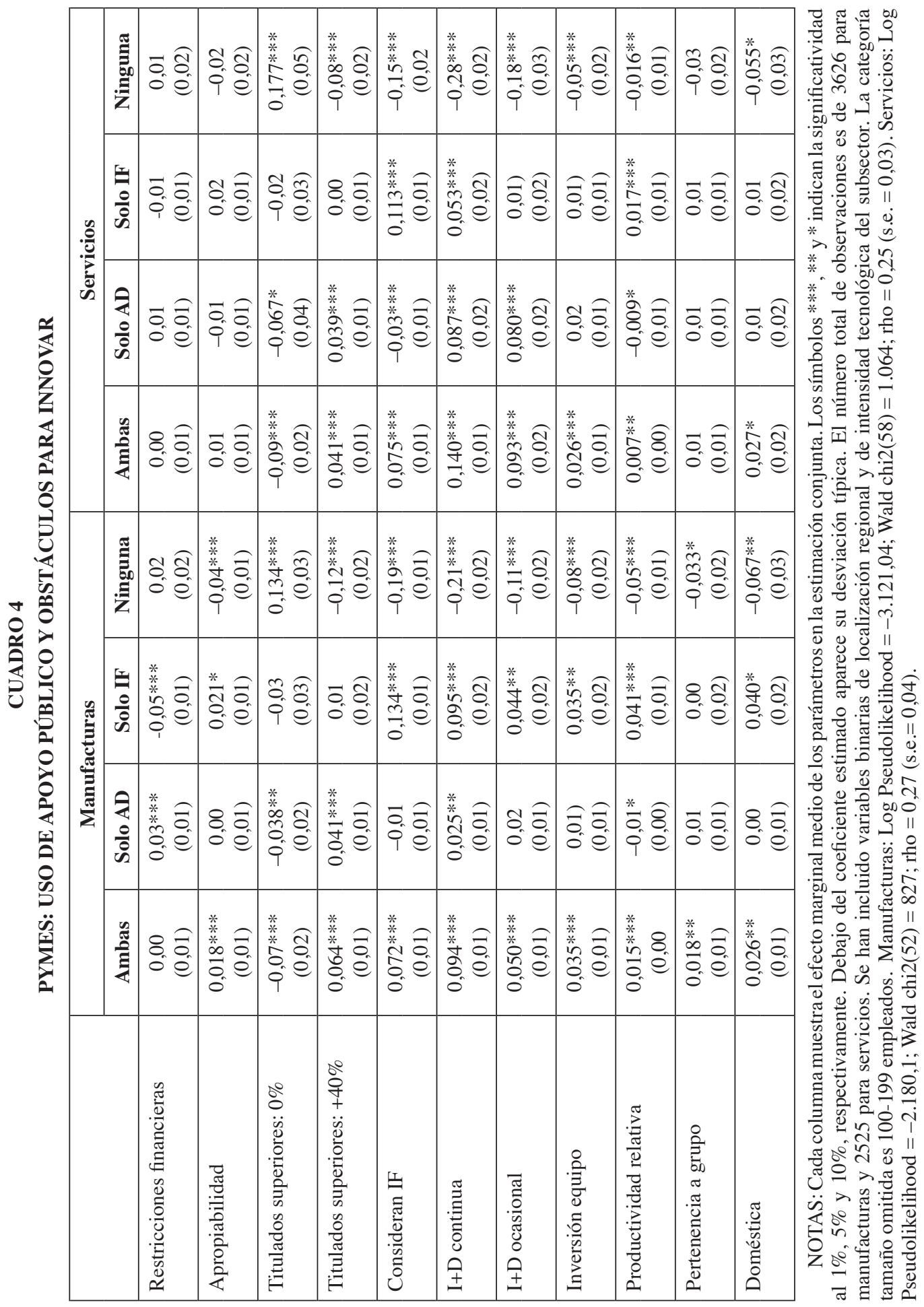




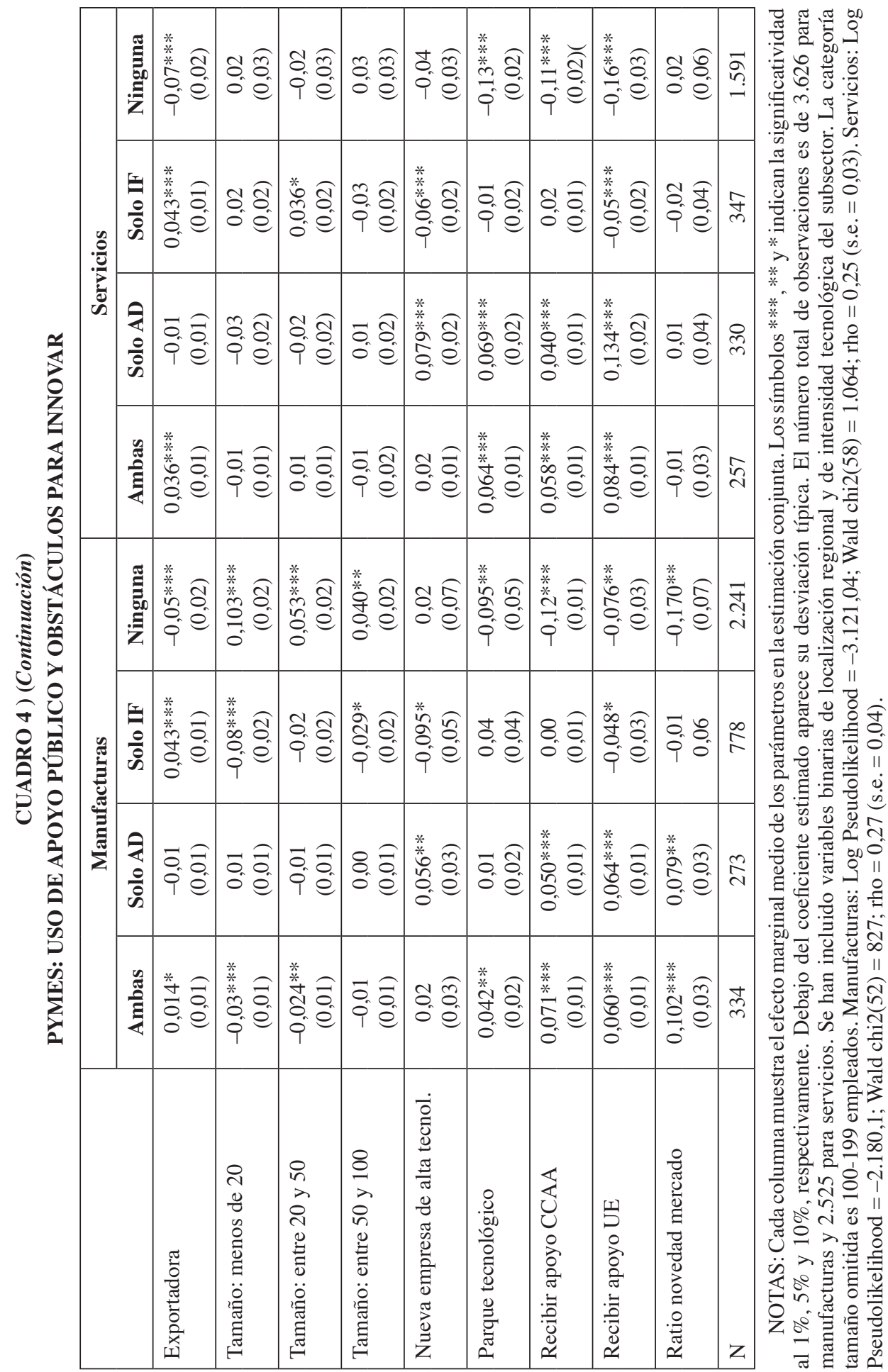




\section{Empresas grandes}

El Cuadro 5 muestra los resultados de las estimaciones para las empresas grandes de los dos sectores. En este caso observamos un comportamiento parecido en ambos sectores por lo que se refiere a las restricciones financieras: la probabilidad de acceder a deducciones fiscales se reduce, mientras que la probabilidad de acceder a ayudas directas aumenta. Como en el caso de las PYMES, el capital humano de la empresa aumenta la probabilidad de utilizar estos instrumentos especialmente en el sector de servicios (la mayoría de empresas manufactureras grandes disponen de un nivel elevado de capital humano, por lo que este no es un factor que las diferencie). La experiencia previa en I+D contribuye positivamente al uso de incentivos fiscales, y en menor medida al uso de ayudas directas, lo que sugiere que si la política pretende estimular la innovación en empresas que no invertían en $\mathrm{I}+\mathrm{D}$, las ayudas directas son un mecanismo para identificarlas más efectivo que los incentivos fiscales.

Todos estos resultados parecen corroborar algunas de las investigaciones recientes, en el sentido que no parece demostrable que exista un sesgo en el uso de políticas públicas hacia el sector manufacturero en detrimento del sector servicios; es más, los efectos asociados a fallos de mercado son parecidos con leves diferencias. Las diferencias más notables derivarían de la distinta distribución de las empresas por tamaños y la disponibilidad de capital humano en las mismas. 


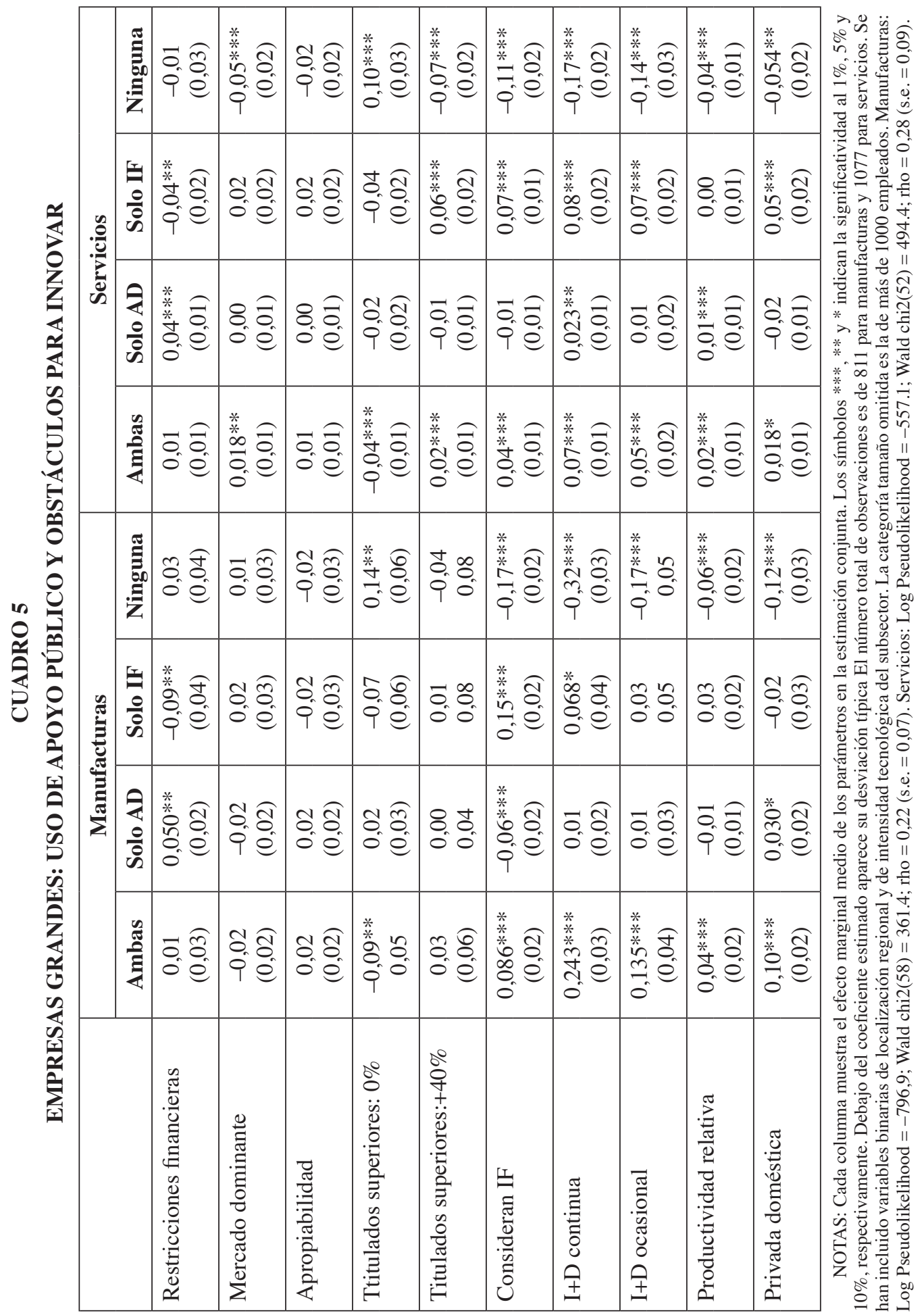




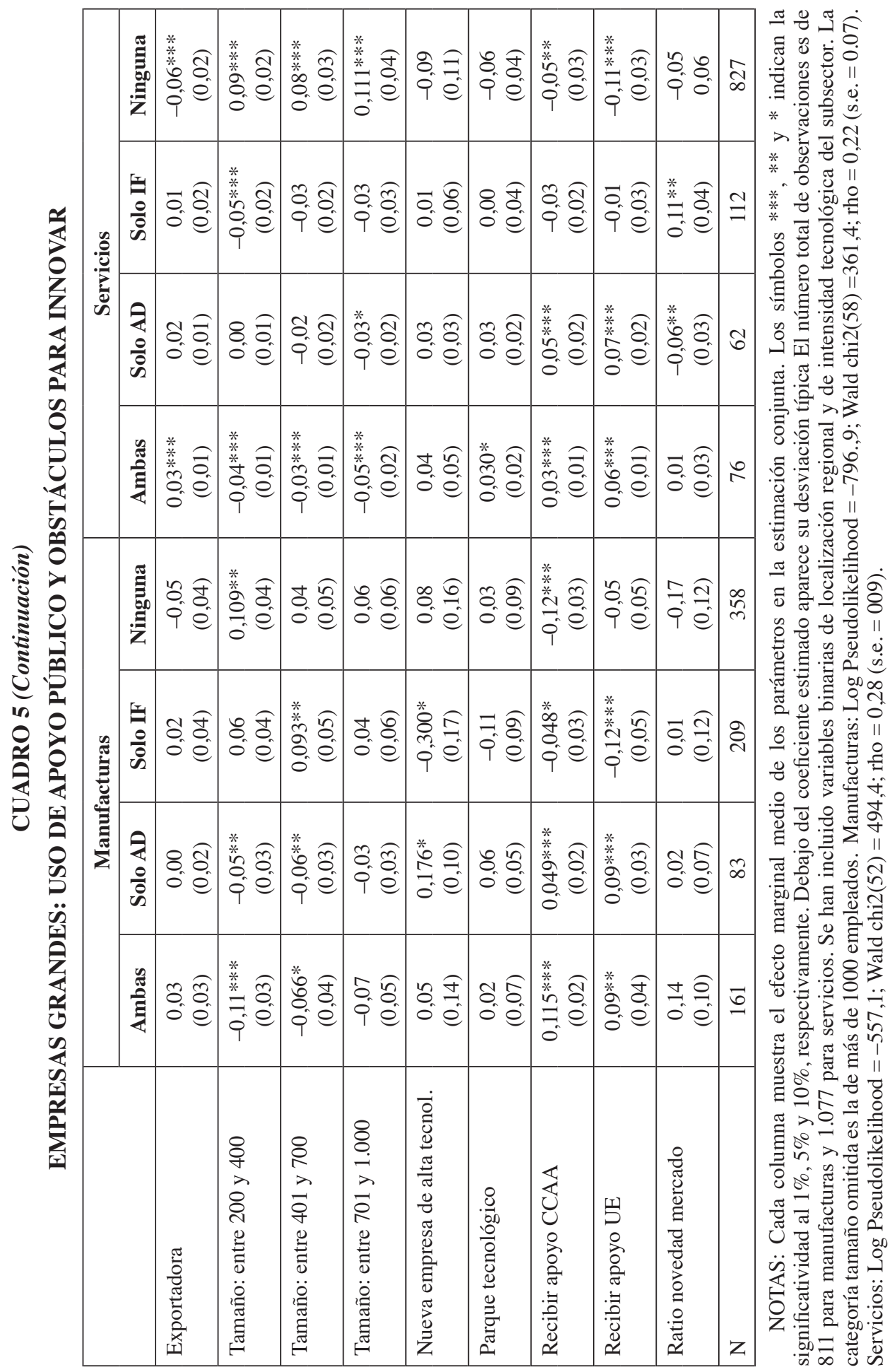




\section{Conclusiones}

La actividad innovadora en los servicios no ha sido tratada y analizada con la misma intensidad que en las manufacturas. En el trabajo que presentamos aquí hemos realizado un análisis comparativo entre manufacturas y servicios en relación con un aspecto concreto: el uso de los instrumentos públicos de estímulo a la I+D privada. El objetivo es ofrecer evidencia de la existencia de diferencias entre ambos sectores y discutir si, en su caso, sería necesario diferenciar también en el diseño de dichos estímulos. El estudio se ha realizado utilizando dos oleadas del PITEC (Panel de Innovación Tecnológica en las Empresas), que proviene de la Encuesta de Innovación Tecnológica en las Empresas que realiza el INE, como parte del proyecto europeo del Community Innovation Survey.

Los períodos estudiados son los de 2003-2005 y 2006-2008. Los principales resultados apuntan que las diferencias observadas en el acceso a dos formas de apoyo público en vigor en España, los incentivos fiscales y las ayudas directas, residen más en el tamaño, capital humano y experiencia previa en I+D de las empresas que en la naturaleza de la actividad productiva. Este resultado permite afirmar que no existe sesgo hacia las manufacturas en materia de estímulos públicos a la actividad innovadora.

Los indicadores de fallos de mercado analizados, apropiabilidad y restricciones financieras, siguen un patrón de comportamiento similar con independencia del sector en el caso de las empresas grandes. Los incentivos fiscales son claramente menos atractivos o accesibles para aquellas que manifiestan enfrentarse a importantes restricciones de financiación de la innovación, al contrario que las ayudas directas. El grado de apropiabilidad no tiene un papel signficativo en ningún caso.

En las PYMES se detecta que las restricciones financieras y la apropiabilidad están asociadas al uso de apoyo público solo para las empresas industriales, pero no para las de servicios. El capital humano y la experiencia previa en I+D son, como en el caso de las empresas grandes, dos de las variables que facilitan el acceso a las dos fuentes de apoyo público. Se pone de manifiesto asimismo que la probabilidad de obtener ayudas directas aumenta para las empresas nuevas basadas en el conocimiento, mientras que la probabilidad de que las mismas accedan a deducciones fiscales se reduce, tanto si se trata de empresas con actividad en el sector de manufacturas como en el de servicios.

En resumen, nuestros resultados señalan, en primer lugar, que a grandes rasgos la facilidad de uso de uno u otro instrumento de fomento de la I+D está asociada a factores comunes para los dos sectores de actividad, destacando el capital humano de cada empresa. Y, en segundo lugar, que cuando las empresas se enfrentan a dificultades de financiación de las actividades de innovación, la evidencia sugiere que las ayudas directas son un instrumento más apropiado que los incentivos fiscales en ambos sectores. Por tanto, no se puede fundamentar, a partir de los datos analizados, la necesidad de desarrollar vías de estímulo sectoriales específicas por lo que se refiere a políticas de innovación en sentido estricto. 


\section{Referencias bibliográficas}

[1] BERUBE, C. y MOHNEN, P. (2009). «Are firms that received R\&D subsidies more innovative?». Canadian Journal of Economics, 42(1), 206-225.

[2] BUSOM, I., CORCHUELO, B. y MARTINEZ-ROS,E.(2014). «Tax credits or subsidies for R\&D?». Small Business Economics, 43(3), 571-596.

[3] CERULli, G. (2010). «Modelling and Measuring the Effect of Public Subsidies on Business R\&D: A Critical Review of the Econometric Literature». Economic Record, 86 (274), 421-449

[4] CZARNITZKI, D. y FIER A. (2002). «Do innovation subsidies crowded out private investment: evidence from the German service sector». Applied Economics Quarterly, $48(1), 1-25$.

[5] COTEC (2010). Informe Cotec 2010. Fundación Cotec para la Innovación Tecnológica.

[6] DAVID, P., HALL, B. y TOOLE, A. (2000). «Is public R\&D a complement or substitute for private R\&D? A review of the econometric evidence». Research Policy, 29(4/5), 497-530.

[7] FALK, M. (2004). «What drives business R\&D intensity across OCDE countries?». Applied Economics, 35(5), 533-577.

[8] FECYT (2010). Informe PITEC 2008: La innovación en la empresa española. Fundación Española para la Ciencia y la Tecnología.

[9] FECYT (2012). Estudios sobre los efectos de la $I+D$ en los resultados empresariales para España.

[10] GELABERT, L., FOSFURI, A. y TRIBÓ, J. (2009). «Does the efect of public support to R\&D depend on the degree of appropiability». The Journal of Industrial Economics, 57(4), 736-767.

[11] GUELLEC, D. y VAN POTTLESBERGHE, B. (2000). «The impact of public R\&D expenditure on business R\&D». DSTI Working Papers 2000/4, OCDE, Paris.

[12] GUELLEC, D. y VAN POTTELSBERGHE, B. (2003). «The impact of public R\&D on business R\&D». Economics of Innovation and New Technologies, 12(3), 225-244.

[13] HALL, B.H. y VAN REENEN, J. (2000). «How effective are fiscal incentives for R\&D? A review of the evidence». Research Policy, 29, 449-469.

[14] HANEL, P. (2003). Impact of Government support programs on innovation by Canadian manufacturing firms. Centre Interuniversitarie de recherche sur la science et la technologie CIRST, Note de Recherche 2003-09.

[15] HUTSCHENREITER, G., POLT, W. y GAISSER, H. (2001). Möglichkeiten zur Erhöhung der Forcshungsquote. Abschätzung der Effekte öffentlicher auf Private F\&E. Ausbagen, Joanneum Research, WIFO, Viena.

[16] KLETTE, T.J., MOEN, J. y GRILICHES, Z. (2000). «Do subsidies to commercial R\&D reduce market failures? Microeconomic evaluation studies». Research Policy, 29, 473497. 


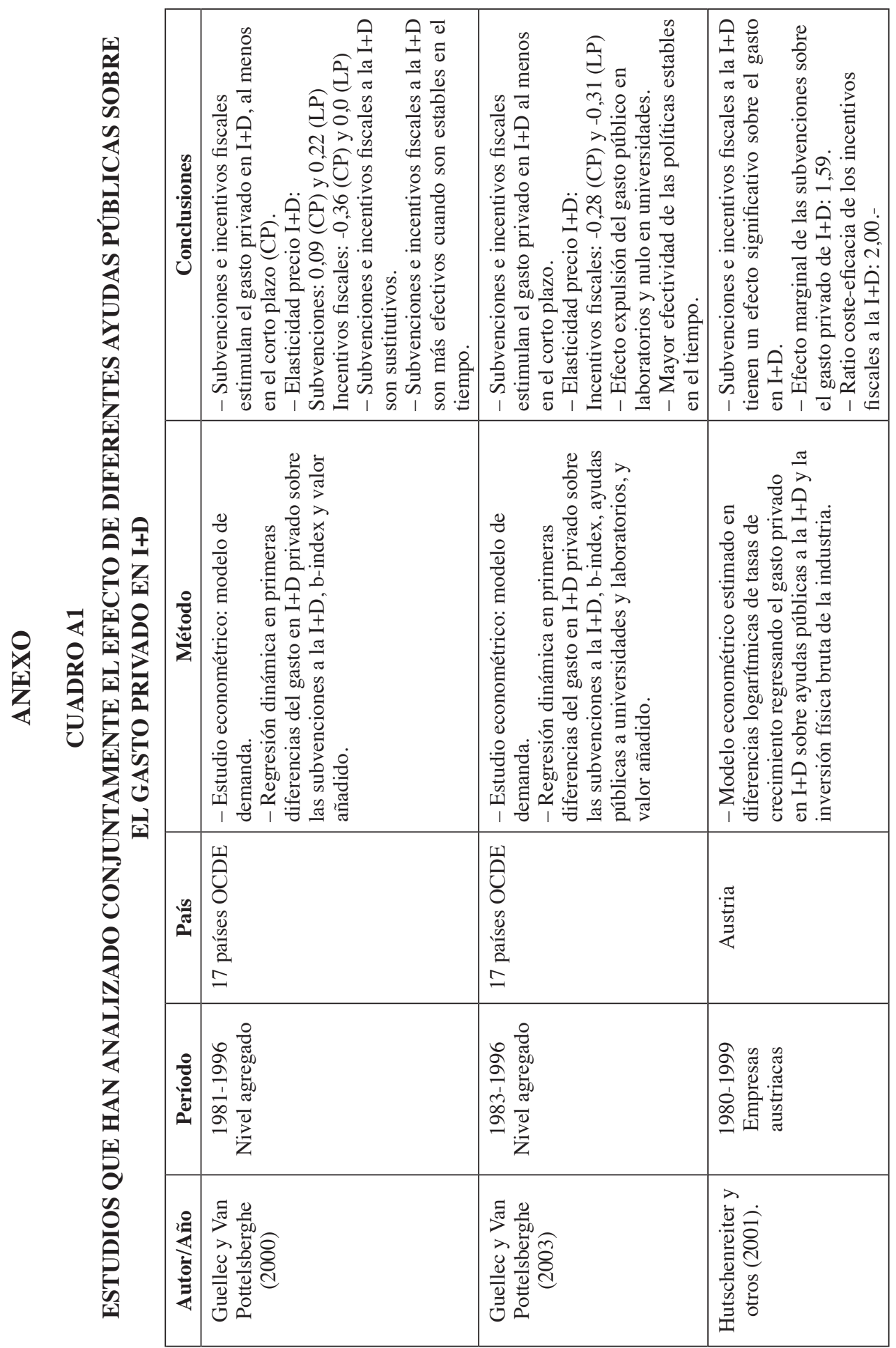




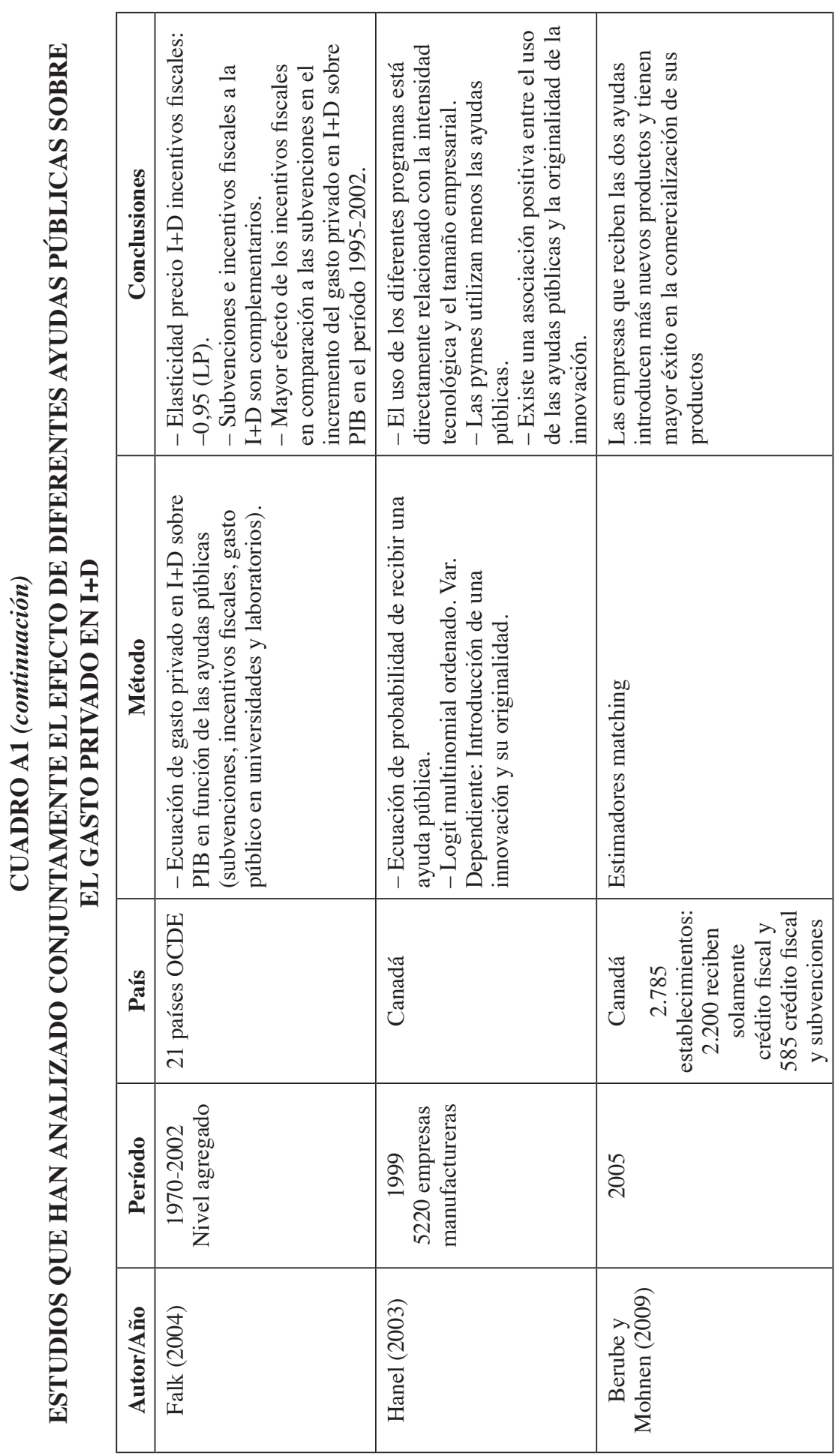




\section{CUADRO A2}

\section{DEFINICIÓN DE LAS VARIABLES EXPLICATIVAS}

\begin{tabular}{|c|c|}
\hline $\begin{array}{l}\text { Restricciones financieras } \\
\text { Mercado dominante } \\
\text { Riesgo de demanda } \\
\text { Falta de personal } \\
\text { Falta de información }\end{array}$ & $\begin{array}{l}\text { Para cada una de estas barreras percibidas, se } \\
\text { computa el ratio entre la valoración dada por la } \\
\text { empresa y el valor medio de todas las barreras } \\
\text { declaradas por cada empresa. }\end{array}$ \\
\hline Apropiabilidad & $\begin{array}{l}\text { Variable binaria que toma valor } 1 \text { si la empresa } \\
\text { usa algún tipo de protección legal de la propiedad } \\
\text { intelectual (copyright, marcas, diseño o patentes). }\end{array}$ \\
\hline Productividad $(\log )$ & $\begin{array}{l}\text { Medida de la distancia de la productividad relativa } \\
\text { de la empresa respecto a la productividad media de } \\
\text { su sector de actividad (expresada en logaritmos). } \\
\text { Las manufacturas se clasifican en } 22 \text { subsectores } \\
\text { y los servicios en } 19 \text { y para cada uno de ellos se } \\
\text { calcula el valor medio de la productividad del } \\
\text { trabajo como ventas/empleados. La productividad } \\
\text { del trabajo de cada empresa en } 2005 \text { se divide por la } \\
\text { media calculada para cada sector. }\end{array}$ \\
\hline Titulados superiores: $0 \%$ & $\begin{array}{l}\text { Variable binaria que toma valor } 1 \text { si la empresa no } \\
\text { tiene empleados con un nivel de educación superior. }\end{array}$ \\
\hline Titulados superiores: $+40 \%$ & $\begin{array}{l}\text { Variable binaria que toma valor } 1 \text { si la empresa tiene } \\
\text { un ratio de empleados con un nivel de educación } \\
\text { superior sobre el total de empleados por encima } \\
\text { del } 40 \% \text {. }\end{array}$ \\
\hline Titulados superiores: hasta $40 \%$ & $\begin{array}{l}\text { Variable binaria que toma valor } 1 \text { si la empresa } \\
\text { tiene un ratio positivo de empleados con educación } \\
\text { superior sobre el total de empleados pero inferior } \\
\text { al } 40 \% \text {. }\end{array}$ \\
\hline Inversión en bienes de equipo & $\begin{array}{l}\text { Variable binaria igual a } 1 \text { si la empresa invirtió en } \\
\text { capital físico en } 2005 \text {, como aproximación a las } \\
\text { expectativas de demanda. }\end{array}$ \\
\hline Considera IF & $\begin{array}{l}\text { Variable binaria igual a } 1 \text { si la empresa tiene en } \\
\text { cuenta las deducciones fiscales potenciales cuando } \\
\text { realiza decisiones de inversión en I+D. }\end{array}$ \\
\hline Pertenecer a un grupo & $\begin{array}{l}\text { Variable binaria que toma valor } 1 \text { si la empresa } \\
\text { pertenece a un grupo de empresas. }\end{array}$ \\
\hline Exportadora & $\begin{array}{l}\text { Variable binaria igual a } 1 \text { si la empresa es } \\
\text { exportadora. }\end{array}$ \\
\hline I+D continua & $\begin{array}{l}\text { Variable binaria igual a } 1 \text { si la empresa declara } \\
\text { realizar actividades de I+D de forma continuada }\end{array}$ \\
\hline I+D ocasional & $\begin{array}{l}\text { Variable binaria igual a } 1 \text { si la empresa declara } \\
\text { realizar actividades de I+D de forma ocasional. }\end{array}$ \\
\hline
\end{tabular}




\section{CUADRO A2 (continuación) \\ DEFINICIÓN DE LAS VARIABLES EXPLICATIVAS}

\begin{tabular}{|c|c|}
\hline Tamaño de la empresa & $\begin{array}{l}\text { Se definen cuatro variables binarias para cada } \\
\text { tamaño empresarial considerado de acuerdo al } \\
\text { número de trabajadores. Para Pymes: menos de } 20 \\
\text { empleados; entre } 20 \text { y } 50 \text {; entre } 51 \text { y } 100 \text {; entre } 101 \\
\text { y } 200 \text {. Para grandes empresas, los intervalos son: } \\
\text { entre } 201 \text { y } 400 \text {; entre } 401 \text { y } 700 \text {; entre } 701 \text { y } 1000 \text {; } \\
\text { y más de } 1000 \text { empleados. }\end{array}$ \\
\hline Nueva empresa de alta tecnología & $\begin{array}{l}\text { Variable binaria igual a } 1 \text { si la empresa se creó } \\
\text { después del año } 2000 \text { y pertenece a sectores de Alta } \\
\text { Tecnología. }\end{array}$ \\
\hline Nueva empresa de nivel tecnológico medio & $\begin{array}{l}\text { Variable binaria igual a } 1 \text { si la empresa se creó } \\
\text { después del año } 2000 \text { y pertenece a sectores de } \\
\text { tecnología media. }\end{array}$ \\
\hline Parque & $\begin{array}{l}\text { Variable binaria que toma valor } 1 \text { si la empresa está } \\
\text { localizada en un parque tecnológico. }\end{array}$ \\
\hline Localización regional & $\begin{array}{l}\text { Tres variables binarias con valor } 1 \text { si la empresa } \\
\text { está localizada en alguna de las siguientes regiones: } \\
\text { Madrid, Cataluña, Andalucía. }\end{array}$ \\
\hline Ratio novedad mercado & $\begin{array}{l}\text { Ratio del número de empresas con innovaciones } \\
\text { nuevas para el mercado en relación al número de } \\
\text { empresas que introducen innovaciones nuevas para } \\
\text { la empresa en el sector de actividad de la misma. }\end{array}$ \\
\hline Recibir subvenciones regionales & $\begin{array}{l}\text { Variable binaria que toma valor } 1 \text { si la empresa ha } \\
\text { recibido algún tipo de subvención del gobierno de la } \\
\text { C. Autónoma. }\end{array}$ \\
\hline Recibir subvenciones UE & $\begin{array}{l}\text { Variable binaria que toma valor } 1 \text { si la empresa ha } \\
\text { recibido algún tipo de subvención procedente de la } \\
\text { Unión Europea. }\end{array}$ \\
\hline
\end{tabular}

